\section{Filosofia da Religião em Kierkegaard depois do anúncio da morte de Deus}

\author{
Jonas Roos \\ Professor adjunto Departamento de \\ Ciência da Religião \\ Programa de Pós-graduação em Ciência da \\ Religião \\ Universidade Federal de Juiz de Fora \\ jonas.roos@ufff.edu.br
}

Resumo: o artigo reflete sobre a atualidade da filosofia da religião de Kierkegaard tomando como inspiração as comemorações dos duzentos anos de seu nascimento e considerando, especialmente, o contexto atual de leitura da obra do dinamarquês como posterior ao anúncio da morte de Deus. Como uma perspectiva de leitura para a filosofia da religião de Kierkegaard abordarei a interpretação de Gianni Vattimo para o anúncio da morte de Deus. Em seguida analisarei alguns aspectos do conceito de histórico como desenvolvido pelo pseudônimo Johannes Climacus no Interlúdio de Migalhas filosóficas e argumentarei que Kierkegaard pensa o Cristianismo de modo não-metafísico, o que aparece, também, em alguns aspectos da forma de sua escrita. Por fim, argumentarei que a kénōsis tanto dá unidade à filosofia da religião de Kierkegaard quanto fornece elementos para pensar sua atualidade.

Palavras-chave: Filosofia da Religião; morte de Deus; histórico; forma de escrita; kénōsis.

\author{
Philosophy of Religion in \\ Kierkegaard after the Death \\ of God
}

\begin{abstract}
: the article reflects on the relevance of Kierkegaard's Philosophy of Religion taking as inspiration the celebration of the two hundred years of his birth and considering especially the current context of reading the work of the Danish philosopher as followed by the announcement of the death of God. As a perspective for reading Kierkegaard's Philosophy of Religion I will discuss the interpretation of Gianni Vattimo for the announcement of the death of God. Then I will analyze some aspects of the concept of the historical as developed by the pseudonym Johannes Climacus in Fragment's Interlude and argue that Kierkegaard thinks Christianity in a nonmetaphysical way, what is also shown in some aspects in the form of his writings. Finally, I will argue that kénōsis both gives unity to Kierkegaard's Philosophy of Religion and provides elements to think about its relevance.
\end{abstract}

Key-words: Philosophy of Religion; Death of God; the Historical; Form of Writing; Kénōsis. 
É sabido que Kierkegaard considerava a si mesmo como um autor religioso ${ }^{1}$. $\mathrm{O}$ que ele mesmo entendia por "religioso", contudo, não é algo simples de se compreender. A inspiração desse texto vem, por um lado, dessa descrição que Kierkegaard dá de si mesmo e do algo enigmático que entendo que ela carrega; por outro lado, a inspiração vem do fato de que, em 2013, comemora-se os duzentos anos de nascimento de Kierkegaard. Como, portanto, podemos compreender o pensamento religioso de Kierkegaard ou, mais especificamente, sua filosofia da religião, duzentos anos depois de seu nascimento, considerando as mudanças operadas ao longo deste período na história da filosofia, especialmente $\mathrm{o}$ anúncio da morte de Deus e suas consequências não só para uma filosofia da religião, mas para o filosofar como um todo?
Se lida com atenção, a obra de Kierkegaard demonstra com bastante clareza que ele articulava o tratamento de problemas específicos a áreas específicas do saber ${ }^{2}$. Não só isso, conteúdos específicos eram discutidos sob formas específicas de escrita. Sua escrita revela constantemente a impossibilidade de separar forma e conteúdo no fazer filosófico. Proponho, nesse texto, compreender alguns elementos da filosofia da religião de Kierkegaard articulando conteúdos específicos com formas específicas de sua escrita e daí tirar implicações para pensar a filosofia da religião na contemporaneidade.

Iniciarei com o anúncio da morte de Deus e com a interpretação de Vattimo para este anúncio entendida como uma perspectiva possível de leitura para a filosofia da religião de Kierkegaard (sem pretender, portanto, uma comparação mais ampla entre Kierkegaard e Vattimo). Em seguida, analisarei alguns aspectos do conceito de histórico como desenvolvido pelo pseudônimo Johannes Climacus no Interlúdio de Migalhas filosóficas e mostrarei que o modo como Kierkegaard concebe o Cristianismo se mostra em alguns aspectos da forma de sua escrita. Se, por um lado, nesse texto procuro abranger um espectro bastante amplo do pensamento de Kierkegaard, por outro tentarei mostrar que a kénōsis dá unidade à totalidade de sua filosofia da religião.

\footnotetext{
${ }^{1} \mathrm{Na}$ introdução do Ponto de vista para a minha obra como autor, Kierkegaard afirma: "O conteúdo, então, deste pequeno livro é: o que em verdade sou como autor, que sou e fui um autor religioso, que toda minha obra pertence ao cristianismo, à questão: tornar-se um cristão, com um foco polêmico direto e indireto com relação à enorme ilusão chamada cristandade ou à ilusão de que neste país todos são cristãos" (KIERKEGAARD, 1998: 23, grifo meu).

${ }^{2} \mathrm{Com}$ respeito a esta questão é bastante esclarecedora a Introdução de $O$ conceito de angústia.
}

Revista de Filosofia Moderna e Contemporânea

Brasília, vol 2, n 1, 2014. 


\section{Nietzsche e o anúncio da morte de Deus}

\begin{abstract}
Não ouviram falar daquele homem louco que em plena manhã acendeu uma lanterna e correu ao mercado, e pôs-se a gritar incessantemente: "Procuro Deus! Procuro Deus!"? - E como lá se encontrassem muitos daqueles que não criam em Deus, ele despertou com isso uma grande gargalhada. Então ele está perdido? perguntou um deles. Ele se perdeu como uma criança? disse um outro. Está se escondendo? Ele tem medo de nós? Embarcou num navio? Emigrou? - gritavam e riam uns para os outros. O homem louco se lancou para o meio deles $e$ trespassou-os com seu olhar. "Para onde foi Deus?", gritou ele, "já lhes direi! Nós o matamos - vocês e eu. Somos todos seus assassinos! Mas como fizemos isso? Como conseguimos beber inteiramente o mar? Quem nos deu a esponja para apagar o borizonte? [...] Não ouvimos o barulho dos coveiros a enterrar Deus? Não sentimos o cheiro da putrefação divina? - também os deuses apodrecem! Deus está morto! Deus continua morto! E nós o matamos! (NIETZSCHE, 2001: 147-148).
\end{abstract}

Não apenas neste fragmento de $A$ Gaia Ciência, mas por toda a sua obra, Nietzsche coloca desafios incontornáveis tanto para o filosofar, em termos amplos, quanto para o pensar sobre o Cristianismo e a religião em nosso tempo. Como, entretanto, interpretar o sentido do anúncio da morte de Deus? Estaríamos aqui diante de uma irrevogável chancela ateísta? Trata-se do fim, não da religião, certamente, mas do fim das possibilidades de se pensar a religião? Ou, ainda, a filosofia da religião, depois deste anúncio, deveria reduzir-se a mero estudo de alguns capítulos da história da filosofia, por certo já ultrapassados? E, se as coisas forem assim, o que resta fazer com um Kierkegaard que, do alto de seus duzentos anos, é um pensador religioso de ponta a ponta? Teríamos de reduzi-lo também a um capítulo da história da filosofia, como alguém que, como sugere Climacus, em Migalhas, participa da evolução da ciência "onde a gente adquire sua legitimação quer como um representante da passagem, da transição, ou da conclusão, quer como um precursor, como participante, como colaborador ou como seguidor voluntário, como herói, ao menos um herói relativo, ou no mínimo como um corneteiro de importância absoluta?" (KIERKEGAARD, 1995: 19).

\section{Vattimo e a interpretação do anúncio da morte de Deus: uma perspectiva para a leitura de Kierkegaard}

Em Depois da cristandade, no capítulo intitulado O Deus que morren, Vattimo nos lembra que, em um dos muitos fragmentos sobre $\mathrm{O}$ niilismo, reunidos em $A$ vontade de potência, Nietzsche afirmara que "'no fundo, somente o Deus moral foi superado"'(VATTIMO, 2004: 19). Vattimo entende que o anúncio da morte de Deus, por Nietzsche, não deve ser interpretado como ateísmo, caso em que tal anúncio ainda guardaria uma estruturação metafísica do real onde a existência ou não existência de Deus poderiam ser entendidas em termos objetivos. Somente uma filosofia que tenha pretensões absolutas pode afirmar a necessidade de um ateísmo. O problema, no entender de Vattimo, é que o ateísmo estabeleceria uma metafísica (enquanto estruturação lógico-necessária na qual a realidade efetiva se espelha) ao revés. Se Giacóia Junior (2000) está correto ao afirmar que o anúncio da morte de Deus significa o fim do modo tipicamente metafísico de pensar, bem compreendido o fim da metafísica não significa o fim das possibilidades de se pensar Deus. Para 
Vattimo, “justamente porque este Deusfundamento último, que é a estrutura metafísica do real, não é mais sustentável, torna-se novamente possível uma crença em Deus". (VATTIMO, 2004: 12). É interessante notar que, para Vattimo (2004), no apogeu dos ateísmos as razões para se negar Deus se ancoravam ou na sua não verificabilidade por meio da experimentação científica ou no entendimento de que esta seria uma fase irremediavelmente superada do processo de iluminação da rąão. Com o fim da metafísica, como pensado por Heidegger, ou com o anúncio da morte de Deus, idêntico, em seu significado, ao fim da metafísica, tais metanarrativas saíram de circulação. Vattimo denomina esses processos como processos de enfraquecimento. Segundo o autor, "é somente neste quadro que o pensamento se conscientiza de que não existem razões fortes para o ateísmo e se abre novamente para a possibilidade da religião" (VATTIMO, 2004: 114). Tal religião, contudo, terá necessariamente de ser repensada em outros termos, talvez afeitos ao que Vattimo entende por enfraquecimento. $O$ paradigma de tal repensar a religião, contudo, não será encontrado fora do cristianismo, mas numa releitura de suas narrativas fundamentais. Para nossa proposta, é iluminador o modo como Vattimo relaciona aquilo que interpreta como a consumação das estruturas fortes do pensamento com aquilo que Paulo chama de kénōsis:

pensar em um curso da bistória que seja orientado na direção da emancipação através da consumação das estruturas fortes [...] não será, na verdade, um modo de transcrever, em termos de filosofia da história, a mensagem cristã da encarnação de Deus, que em São Paulo se chama também kénōsis, isto é, rebaixamento, bumilhação, enfraquecimento de Deus? (VATTIMO, 2004:115).
Entendo que Kierkegaard pensa o cristianismo não como um conjunto de certezas metafísicas, mas como uma possibilidade de construção de sentido. $\mathrm{O}$ paradigma fundamental dessa possibilidade de construção é o paradoxo do Deus rebaixado, esvaziado, fraco, da kénōsis. Em Migalhas Filosóficas, o paradoxo é identificado com o conceito de instante. $\mathrm{O}$ conceito de instante, contudo, é dependente de um entendimento específico do bistórico. Daí que, à época da redação de Migalhas Kierkegaard (1985) anote em seus diários que o bistórico é o aspecto essencial do Cristianismo. Se Kierkegaard pensa sempre o Cristianismo em conexão com a existência e se a existência é entendida como um processo que se realiza na finitude e temporalidade, toda essa concepção está amarrada a um conceito de temporalidade que é radicalmente crítico à introdução da necessidade no processo histórico. Temos, aqui, uma desconstrução do modo tipicamente metafísico de pensar tanto a existência quanto o Cristianismo. Com relação a isso, são cruciais alguns desenvolvimentos de Climacus no Interlúdio de Migalhas.

\section{Sobre o conceito de histórico no interlúdio de Migalhas e suas consequências para o conceito de cristianismo}

Todo fato histórico, à medida que surgiu, está no âmbito do devir e, nesse sentido, se opõe ao necessário. Segundo Climacus: "nenhum devir é necessário; nem antes de devir, pois desse jeito não pode devir; nem depois que deveio, pois neste caso não deveio." (KIERKEGAARD, 1995: 108). Segundo Evans (1992), Climacus é tão veemente neste ponto que recusa a distinção aristotélica entre duas espécies de 
possível em relação ao necessário. Para Aristóteles, o necessário é possivel, já que não pode ser impossivel. Entretanto, aquilo que é apenas possivel, meramente possivel, pode não existir. Daí se poderia concluir que aquilo que é necessário e deve existir é também possível e, nesse sentido, poderia não existir. Para escapar desta contradição, Aristóteles distingue entre a mera possibilidade e a possibilidade que a necessidade inclui. Embora não discuta a questão em pormenor, Climacus se aplica a sustentar uma distinção cortante entre o possível e o necessário, de modo a não aceitar as distinções dos dois tipos de possibilidade de Aristóteles em relação ao necessário. Com relação à distinção aristotélica, Climacus afirma que o erro desta estaria em não perceber que o possível não se deixa predicar do necessário.

Se for verdadeiro que o que veio a ser aconteceu como aconteceu por liberdade e não por necessidade, isso que veio a ser nunca poderá ser conhecido em uma necessidade, que, aliás, não possui. Todo fato histórico só pode ser conhecido em sua contingência. Nada do que é histórico conduz a uma certeza necessária. Note-se que Climacus intensifica a tensão dialética da pergunta inicial de Migalhas sobre a possibilidade de se construir uma felicidade eterna sobre um saber historico.

Mas, com relação ao exposto, não poderíamos objetar que o fato de que algo tenha acontecido, o tornaria necessário? $\mathrm{E}$ se, por ter acontecido, tivesse se tornado necessário, não poderia, então, ser conhecido necessariamente? A relação entre o devir e o histórico tem, portanto, consequências para o modo como se pode compreender um fato histórico e, em última análise, relacionar-se com o histórico mesmo.
O que aconteceu não pode ser refeito, não pode ser mudado. Neste sentido dizemos que se tornou necessário. Com relação a isso Climacus se pergunta se a imutabilidade do passado é a da necessidade. Cito Climacus:
A imutabilidade do passado consiste em que o "assim" de sua realidade não pode vir a ser diferente; mas segue-se dai que o "como" possivel deste passado não teria podido vir a ser de outra maneira? A imutabilidade do necessário, bem ao contrário, consiste no relacionar-se sempre consigo mesmo e relacionar-se sempre consigo do mesmo modo. (KIERKEGAARD, 1995: 111).

O fato acontecido carrega em si a imutabilidade do bistórico. Entretanto, a imutabilidade daquilo que aconteceu é diferente de uma necessidade metafísica. $\mathrm{O}$ necessário no sentido da metafísica é aquilo que não pode ser concebido de outro modo. O histórico, entretanto, tem outra característica: “o passado não se tornou mais necessário por ter acontecido, mas ao contrário mostrou, por ter acontecido, que não era necessário" (KIERKEGAARD, 1995: 111-112). Claro que depois de ter acontecido não pode ser mudado, entretanto aconteceu justamente porque era possível e, neste sentido, poderia, perfeitamente, não ter acontecido. Historicidade e contingência estão ligadas. Embora não o diga explicitamente, parece claro para Kierkegaard que pretender conhecer a necessidade de um fato histórico implicaria conhecer algo histórico privando-o de sua historicidade!

Climacus resgata a noção cristã de que o mestre, em seu esvaziar-se, tornou-se igual ao discípulo para que ambos se compreendessem, já que, diferentemente do socrático, não havia uma relação inicial de reciprocidade entre eles. A partir disso, poder-se-ia concluir que, à medida que o 
Filosofia da Religião em Kierkegaard depois do anúncio da morte de Deus

eterno se faz presente no histórico a partir da igualdade operada no esvaziamento de Deus, no seu próprio revelar-se, o eterno se torna manifesto em sentido objetivo. Para Kierkegaard, entretanto, a igualdade estabelecida no rebaixamento do mestre mantém a incompreensibilidade. Climacus chega mesmo a sugerir que, ao estabelecer a igualdade, o eterno se torna, de certo modo, mais incompreensível do que permanecendo em sua diferença. Em Migalhas, afirma: "Pois é menos espantoso cair com o rosto no chão quando as montanhas tremem à voz do deus do que estar sentado junto dele como ao lado de um igual, e no entanto esta é afinal de contas a preocupação do deus, sentar-se justamente desta maneira!" (KIERKEGAARD, 1995: 58). A articulação entre temporal e eterno é fundamental tanto para o correto entendimento do histórico como para o sentido da existência, mas não do ponto de vista de uma análise objetiva, distanciada.

Pensando a questão em termos da figura central do Cristianismo, para uma análise objetiva do histórico, o mestre mantém-se indisponivel. Cito Climacus novamente: "[...] é fácil ao discípulo contemporâneo tornarse testemunha ocular; a infelicidade, porém, consiste em que o fato de conhecer uma circunstância histórica, sim, até mesmo conhecer todas as circunstâncias históricas com a certeza da testemunha ocular, de maneira alguma transforma uma testemunha ocular num discípulo." (KIERKEGAARD, 1995: 88). O que transforma alguém em discípulo, nesse entendimento, é o assumir um modo de existência.

Tais discussões que procuram escavar conceitos $^{3}$ que, nesta leitura, são fundamentais para a compreensão da filosofia da religião de Kierkegaard, encontrarão importantes ecos nos trabalhos do jovem Heidegger de Fenomenologia da vida religiosa. Para este autor, um dos conceitos fundamentais para que se entenda o Cristianismo de Paulo, como articulado em sua carta aos tessalonicenses, é o de parusía, a segunda vinda de Cristo. Este elemento é importante para uma compreensão específica da temporalidade, que é diferente da platônica. A parusía está indisponível enquanto evento e não é algo que se pode conhecer do mesmo modo que se pode conhecer outras coisas. É fundamental, para Heidegger, em sua análise, o texto de I Tessalonicenses 5.1-4:

Irmãos, relativamente aos tempos e às épocas,
não há necessidade de que eu vos escreva; pois
vós mesmos estais inteirados com precisão de
que o Dia do Senhor vem como ladrão de
noite. Quando andarem dizendo: Paz, e
segurança, eis que lhes sobrevirá repentina
destruição, como vem as dores do parto à que
está para dar à lũ̃; e de nenhum modo
escaparão. Mas vós, irmãos, não estais em
trevas, para que esse Dia como ladrão vos
apanhe de surpresa.

Heidegger observa que Paulo, ao responder a pergunta pelo quando da parusía, demonstra que a entende como não sujeita ao cálculo. O que entra em jogo nessa

3 Esta imagem da escavação de conceitos, talvez soterrados por séculos de incompreensão, é refletida pelo próprio Kierkegaard, em seu diário, ao pensar no naturalista dinamarquês, e seu parente distante, Wilhelm Lund, que na época vivia no Brasil, em Lagoa Santa, MG. Kierkegaard escreve: "Wilhelm Lund / Hoje me ocorreu a similaridade entre a sua vida e a minha. Assim como ele vive lá no Brasil, perdido para o mundo, absorto escavando fósseis antediluvianos, assim eu vivo como se estivesse fora do mundo, absorto escavando conceitos cristãos - ai, e, no entanto, eu estou vivendo na cristandade, onde o cristianismo floresce, encontra-se em exuberante crescimento com seus mil pastores, e onde nós somos todos cristãos” (KIERKEGAARD, 1967-78, vol. 6, p. 337 [JP VI 6652, Pap. X3 A 239 n.d., 1850]). 
questão é aquilo que os tessalonicenses se tornaram, seu próprio modo de vida. A rigor, é a partir disso que surge o quando, o instante. Segundo Heidegger,

Toda a questão, para Paulo, não diz respeito à

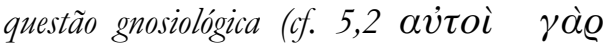

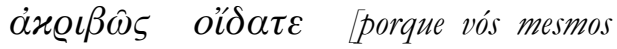
sabeis muito bem]). Ele não diz: "nesse on naquele momento o Senhor virá novamente"; também não diæ: "não sei quando ele voltará", mas ele diz: "Vós sabeis muito bem..." Este saber deve ser um saber todo peculiar, pois Paulo remete os tessalonicenses a si mesmos e o saber que possuem a respeito do seu ter-setornado. A partir desse modo de contestar segue-se que a decisão da "pergunta" depende de sua própria vida (HEIDEGGER, 2010: 91).

Tanto para Kierkegaard quanto para o jovem Heidegger é necessário pressupor, no contexto dessas discussões, um entendimento de temporalidade que seja diferente do platônico. Para Heidegger o entendimento platônico geraria um asseguramento com relação à temporalidade. A forma e o sentido deste "se realizam mediante a construção de uma teoria sobre o sentido da realidade do temporal. À medida que conheço que tipo de sentido de realidade tem o temporal, este perde seu caráter inquietante para mim, já que o reconheço como uma conformação do supratemporal” (HEIDEGGER, 2010: 44). Evidentemente que, enquanto seres naturais, estamos imersos na temporalidade assim como o está a natureza. $\mathrm{O}$ uso que fazemos de nossa liberdade, entretanto, constitui um devir no interior desse devir. Esta é a dialética pressuposta em $A$ Doença para a Morte, do pseudônimo AntiCliamcus. Toda pessoa nasce humana enquanto união de elementos polares. Tornar-se si mesmo, entretanto, implica colocar a si mesmo em movimento, em gerar um devir que é interior a este primeiro devir. Isso implica, entretanto, em abrir mão de uma segurança com relação à temporalidade que, tanto para Kierkegaard quanto para Heidegger, o cristianismo, pelo menos em suas acepções mais originárias, não oferece.

\section{Incerteza objetiva}

O paradigma fundamental para este entendimento de Cristianismo é a kénōsis, o entendimento do Deus que se esvazia, rebaixa, e se mostra como fraco, como paradoxo. A filosofia da religião que queira refletir a partir desse núcleo não poderá implicar a constituição de um sistema que dê conta de explicar de modo final a realidade do paradoxo. A reflexão sobre o Cristianismo será, portanto, uma proposta de construção de sentido que convive com a possibilidade de escândalo ou, se quisermos, para usarmos uma formulação constante em Temor e tremor, com a angústia, a tribulação e o paradoxo. Deve se dar atenção ao fato de que uma imagem de Kierkegaard para o cristão (1992, 1988, 1967-1978) é a da pessoa flutuando numa profundidade abissal, sobre 70.000 braças d'água. Não há um ponto fixo no qual se agarrar. Religião, para Kierkegaard, não é isso. Não se pode eliminar a dúvida ou a possibilidade de escândalo nos processos da existência, não há outra saída.

É nesse sentido que em Pós-escrito Kierkegaard falará constantemente da incerteza objetiva implicada no Cristianismo. O pano de fundo dessa formulação remete ao problema de Migalhas: o de como construir uma felicidade eterna sobre um saber histórico. Se todo saber histórico, à media que está no âmbito do devir, é contingente, coloca-se uma descontinuidade radical entre este e uma felicidade eterna, 
que é o que propõe o Cristianismo. Não há acúmulo de conhecimento no âmbito do histórico que gere uma felicidade eterna. Isso porque todo conhecimento histórico é sempre aproximativo. Por mais que sua quantidade aumente, ele nunca poderá gerar uma nova qualidade, a passagem a uma felicidade eterna. Ou seja, terá que assumir a incerteza objetiva; e não como algo a ser superado, mas como algo que é constitutivo da religião e, se quisermos, da própria existência. A única possibilidade de superação dessa descontinuidade, então, será a paixão e o interesse infinitos gestados no âmbito mesmo da incerteza objetiva.

Atentemos agora para como alguns desses conteúdos se manifestam na forma de escrita em Kierkegaard.

\section{Filosofia da Religião e a relação entre forma e conteúdo}

Quer sob seu próprio nome, quer sob pseudônimos, Kierkegaard faz filosofia da religião em conexão com o pensar a existência enquanto constrói seus personagens e personifica conceitos. Daí Fausto, o judeu errante, o sedutor, Abraão, Jó, Adão, o discípulo, o mestre, a pessoa amorosa, a pessoa desesperada etc. Seu objetivo é a compreensão da existência em relação com o Cristianismo. A existência, contudo, é processo. Por isso a personificação de conceitos. Ao descrever um personagem o autor tem em mãos o recurso para enfatizar as diferentes gradacõos vividas no processo, tem em mãos o recurso para modular o conceito.

Incerteza objetiva é justamente o que experimenta aquele que é entendido por Kierkegaard como modelo de fé, como aquele que fornece a forma da fé. Personificada em Abraão, a fé não é pensada como um conhecimento objetivo sobre determinadas proposições, mas como um pôr-se a caminho numa atitude de envolvimento existencial e interioridade 4 . Bem no início de Temor e tremor lemos que "a prática da dúvida não se adquire em alguns dias ou poucas semanas"(KIERKEGAARD, 1983: 6), e, logo abaixo: "a aptidão para crer não se adquire em alguns dias ou poucas semanas" (KIERKEGAARD, 1983: 7). A fé se articula na incerteza objetiva e, portanto, com a dúvida. Se Kierkegaard, através da pena de Johannes de Silentio, poderia ter escolhido várias imagens para representar a fé, é interessante notar que aquele que é o paradigma da fé não é descrito lendo um texto sagrado, em oração, em meditação ou refletindo. Ele é como que pintado nos diversos quadros de uma caminhada. É desse modo que Temore Tremor constitui, nas palavras de Kierkegaard em Ponto de vista, "um tipo muito singular de produção estética" para o "observador sério que tem à sua disposição os pressupostos religiosos" (KIERKEGAARD, 1998: 37). É na pintura dos quadros dessa caminhada que temos desenhado o entendimento de fé, algo do modo de Kierkegaard conceber e pensar o Cristianismo e, consequentemente, de fazer filosofia da religião. Será característica

\footnotetext{
${ }^{4}$ Neste texto quero enfatizar que a fé, no entendimento de Kierkegaard, envolve uma atitude de envolvimento existencial e interioridade. Por isso mesmo, a fé não pode ser entendida como mero conhecimento objetivo ou como conhecimento de um corpo de doutrinas. Disso não segue, contudo, que a fé não possa ser articulada em formulações doutrinárias. O problema, para Kierkegaard, parece ser o da redução da fé ao conhecimento objetivo.
}

Revista de Filosofia Moderna e Contemporânea

Brasília, vol 2, no 1, 2014. 
fundamental desse entendimento a personificação de conceitos onde o leitor é convidado a acompanhar um processo de desconstrução e construção de sentido.

Enfatizando agora a descrição de processos e a modulação de conceitos, notemos como Anti-Climacus, em $A$ doença para a morte, usa alguns termos que, à primeira vista, podem passar despercebidos, mas que são reveladores para o modo como constrói seu pensamento e, consequentemente, para a compreensão dos conteúdos que articula. Com bastante frequência aparecem os termos "nu" e "saa", simplesmente "agora" e "então" - indicando o movimento temporal, a transição. Embora haja usos variados para esses termos, o número de ocorrências é significativo para um livro de cerca de 130 páginas: "nu" (agora) aparece 110 vezes e "saa" (então) aparece 537 vezes! Ao invés de dizer simplesmente "o desespero é", ele insere no texto a figura de pessoas em desespero e, então, explora variações e gradações, explora as nuances do processo que é tornar-se si mesmo.

Como vimos, o Cristianismo é pensado por Kierkegaard fundamentalmente como um processo de tornar-se que acontece na temporalidade; para a descrição desses processos é fundamental, e de modo algum ocasional, a personificação de conceitos. Por razões análogas será importante para o entendimento que proponho nesse texto, que a filosofia da religião de Kierkegaard não seja concebida em tratados, mas na elaboração de discursos: discursos edificantes; discursos cristãos; discursos em situações imaginárias; discursos edificantes em vários espíritos etc. Note-se que já na primeira frase da primeira coleção de discursos que publicou Kierkegaard (1990) afirme que, enquanto autor dos discursos, não tem autoridade. Os discursos não dizem respeito a uma construção de sentido externa ao indivíduo à qual deva fazer um esforço moral e intelectual para compreender. São, antes, uma proposta de construção de sentido, uma proposta de edificação que lançam a autoridade para o leitor. O leitor deve decidir se a elaboração dos conceitos que ali se encontram são ou não uma proposta coerente de construção de sentido no horizonte do Cristianismo.

\section{Conclusão: Cristianismo, kénōsis e o nosso tempo}

A relação para com o cristianismo é processo porque a existência é processo. $\mathrm{E}$ um processo em que não há certezas objetivas. Vemos, novamente, que seu conceito de cristianismo é, de certo modo, fraco. Mas não será fraco demais?

Kierkegaard herda de Hegel a percepção da importância do conceito de absoluto. A relação para com o absoluto, contudo, em Kierkegaard, não é dada pelo conbecimento absoluto do absoluto, mas numa relação absoluta com o absoluto pela via da fé entendida enquanto paixão. Kierkegaard, aqui, está muito próximo e muito distante de Hegel. Quando, contudo, esta paixão é assumida, assume-se também um rigor conceitual e lógico na consistência interna onde esta paixão se articula.

Religião, enfim, diz respeito à construção de sentido para a existência (que se articula em termos simbólicos). Em nosso tempo, tal sentido não pode ser mero reflexo de um conhecimento que se pretenda necessário, o que, como vimos, já está muito bem elaborado em Kierkegaard.

Por outro lado, se o Cristianismo é concebido nos moldes de um tão comum 
platonismo para o povo, e se Deus vem a ser entendido como uma engrenagem da mecânica da realidade, temos aí aberta a porta para uma muito bem-vinda secularização. À medida que se aprende a manipular de modo competente a realidade, esse deus vem a se tornar uma peça desnecessária dessa mecânica (e, digase de passagem, nesse entendimento a secularização não teria sido gerada pelos discursos anti-teológicos mas seria um desdobramento de certas teologias). De qualquer modo, vendo a religião sob esta ótica, penso que Kierkegaard concordaria não apenas com o trecho de A Gaia Ciência lido inicialmente, mas também, e sobretudo, com o seu final:

\begin{abstract}
Conta-se também que no mesmo dia o homem louco irrompeu em várias igrejas, e em cada uma entoou o seu Requiem aeternum deo. Levado para fora e interrogado, limitava-se a responder: "O que são ainda essas igrejas, se não os mausoléus e túmulos de Deus?" (NIETZSCHE, 2001:148).
\end{abstract}

\section{Referências bibliográficas}

BÍBLIA DE ESTUDO ALMEIDA. Trad. de João Ferreira de Almeida. Ed. rev. e atualizada no Brasil. Barueri, SP: Sociedade Bíblica do Brasil, 1999.

EVANS, C. Stephen. Passionate Reason: making sense of Kierkegaard's Philosophical Fragments. Bloomington \& Indianapolis: Indiana University Press, 1992. (The Indiana Series in the Philosophy of Religion).

GIACÓIA JÚNIOR, Oswaldo. Nietəsche. São Paulo. Publifolha, 2000.

HEIDEGGER, Martin. Fenomenologia da Vida Religiosa. Trad. de Enio Paulo
Giachini, Jairo Ferrandin, Renato Kirchner. Petrópolis, RJ: Vozes; Bragança Paulista, SP: Editora Universitária São Francisco, 2010.

KIERKEGAARD, Søren A. O conceito de angústia: uma simples reflexão psicológico-demonstrativa direcionada ao problema dogmático do pecado hereditário, de Vigilius Haufniensis. Trad. e posfácio de Álvaro Luiz Montenegro Valls. Petrópolis, RJ: Vozes; Bragança Paulista, SP: Editora Universitária São Francisco, 2010.

The Point of View on my work as an Author, The Point of View for my work as an Author, Armed Neutrality. Ed. e trad. com introdução e notas de Howard V. Hong e Edna H. Hong. New Jersey: Princeton University Press, 1998.

Migalhas Filosóficas: ou um bocadinho de filosofia de João Clímacus. Trad. de Ernani Reichmann e Alvaro L. M. Valls. Petrópolis, RJ: Vozes, 1995.

Concluding Unscientific Postscript to Philosophical Fragments. Ed. e trad. com introdução e notas de Howard V. Hong e Edna H. Hong. v. I e II. New Jersey: Princeton University Press, 1992.

Eighteen Upbuilding Discourses. Ed. e trad. com introdução e notas de Howard V. Hong e Edna H. Hong. New Jersey: Princeton University Press, 1990.

Stages on Life's Way. Ed. e trad. com introdução e notas de Howard V. Hong e Edna H. Hong. New Jersey: Princeton University Press, 1988. 
Jonas Roos

Philosophical Fragments - Johannes Climacus. Ed. e trad. com introdução e notas de Howard V. Hong e Edna H. Hong. New Jersey: Princeton University Press, 1985.

Fear and Trembling - Repetition. Ed. e trad. com introdução e notas de Howard V. Hong e Edna H. Hong. New Jersey: Princeton University Press, 1983.

The Sickness unto Death. Ed. e trad. com introdução e notas de Howard V. Hong e Edna H. Hong. New Jersey: Princeton University Press, 1980.

- Soren Kierkegaard's Journals and Papers. Ed. e trad. de Howard V. Hong e Edna H. Hong com auxílio de Gregor Malantschuk. v. 1-6, v. 7 Index. Bloomington, London: Indiana University Press, 1967-78. (versão eletrônica).

- Tvende ethisk-religieuse Smaa-

Afbandlinger - Sygdommen til Doden. Ed. por A. B. Drachmann, J. L. Heiberg e H. O. Lange. 3 ed. København: Gyldendal, 1962.

NIETZSCHE, Friedrich Wilhelm. A Gaia Ciência. Trad. notas e posfácio de Paulo César de Souza. São Paulo: Companhia das Letras, 2001.

VATTIMO, Gianni. Depois da Cristandade. Trad. de Cynthia Marques. Rio de Janeiro: Record: 2004.

Revista de Filosofia Moderna e Contemporânea

Brasília, vol 2, no 1, 2014. 